\title{
Smoking and erectile dysfunction: findings from a representative sample of Australian men
}

\author{
C Millett, L M Wen, C Rissel, A Smith, J Richters, A Grulich, R de Visser
}

Tobacco Control 2006;15:136-139. doi: 10.1136/tc.2005.015545

See end of article for authors' affiliations

.....................

Correspondence to Dr Li Ming Wen, Health Promotion Unit (Eastern Zone), Sydney South West Area Health Service, Leve 9 North, King George V Building, Missenden Road Camperdown NSW 2050

Australia; Imwen@email.

cs.nsw.gov.au

Received 19 December 2005

Accepted 22 December 2005
Objectives: To examine whether there is an association between smoking and erectile dysfunction in a representative sample of Australian men.

Design: Secondary analysis of cross-sectional survey data from the Australian Study of Health and Relationships.

Participants: 8367 Australian men aged 16-59 years.

Main outcome measures: Erectile dysfunction was identified in men who reported having had trouble keeping an erection when they wanted to, a problem which persisted for at least one month over the previous year. Variables examined in multivariate logistic regression analyses included age, education, presence of cardiovascular disease and diabetes, and current alcohol and tobacco consumption.

Results: Almost one in 10 of the respondents (9.1\%) reported erectile dysfunction that lasted for at least one month over the previous year. More than a quarter $(27.2 \%)$ of respondents were current smokers, with $20.9 \%$ smoking $\leqslant 20$ cigarettes per day, and $6.3 \%$ smoking $>20$ cigarettes per day. Compared with non-smokers, the adjusted odds ratios for erectile dysfunction were 1.24 (95\% confidence interval (Cl) 1.01 to $1.52, p=0.04$ ) for those smoking $\leqslant 20$ cigarettes per day and $1.39(95 \% \mathrm{Cl} 1.05$ to 1.83 , $p=0.02$ ) for those smoking $>20$ cigarettes per day, after adjusting for other confounding factors. Older age, low level of education, and taking medications for cardiovascular disease were also independently and positively associated with erectile dysfunction. In contrast, moderate alcohol consumption (1-4 drinks per day) significantly reduced the likelihood of having erectile dysfunction.

Conclusions: Erectile dysfunction is a significant health concern affecting around one in 10 Australian men aged 16-59 years. Current smoking is significantly associated with erectile dysfunction in Australian males. This association was strengthened as the number of cigarettes smoked increased. Health promotion programmes could use the link between smoking and erectile dysfunction to help reduce smoking levels among men.
A ustralian men are much more likely than women to be daily smokers (19\% compared to $16 \%$ ) with the highest smoking rate $(24 \%)$ among those aged $20-29$ years. ${ }^{12}$ This younger group may be less receptive to conventional tobacco control messages, which typically focus on risks of potentially distant events such as cardiovascular disease and lung cancer. Evidence of a link between smoking and erectile dysfunction has been little used as a means of persuading male smokers to quit, ${ }^{3}$ although recent tobacco control efforts in California have targeted young smokers with this message, ${ }^{5}$ as have graphic cigarette pack warnings in Brazil and Thailand. ${ }^{6}$

Studies have suggested an association between smoking and erectile dysfunction. However, much of the accumulated evidence has been derived from clinical settings. ${ }^{7}$ Very few population-based studies have examined this link and evidence supporting a causal relationship between smoking and erectile dysfunction remains limited. The Massachusetts Male Aging Study, a cohort study of men aged $40-70$ years living in the Boston area, found that cigarette smoking at baseline almost doubled the likelihood of moderate or complete erectile dysfunction at follow-up, after controlling for other risk factors. ${ }^{9}$ In another study, Mannino et a ${ }^{10}$ reported that in a study of 4462 Vietnam war veterans aged 31-49 years, smokers were one and a half times more likely to report impotence than non-smokers. However, these findings were weakened by their selective study populations.

In this study we examined factors that are associated with erectile dysfunction in a large, representative sample of 8367 Australian men aged 16-59 years using data from the 2001
Australian Study of Health and Relationships (ASHR), a major national survey of sexual and reproductive health. Its study population was generated using modified random digit dialling telephone survey methodology for all the states of Australia. ${ }^{11}$

\section{METHODS}

The ASHR was a major cross-sectional survey of a representative sample of adults aged 16-59 years covering a wide range of sexual and reproductive health issues. A total of 19307 respondents ( 10173 men, 9134 women) completed a computer-assisted telephone interview between mid-2001 and mid-2002. The response rate for men was 69\%. Full details of the study methods have been described elsewhere. ${ }^{11}$ The study protocol was approved by the Human Ethics Committees of La Trobe University, the University of New South Wales and the Central Sydney Area Health Service.

\section{Study sample and data collection}

We analysed ASHR data for male respondents who reported being sexually active over the past 12 months, using a broad definition which covered sexual intercourse and masturbation. The study outcome variable was self-reported erectile dysfunction which was assessed using the question: "During the past year has there been a period of one month or more when you had trouble keeping an erection when you wanted to?" Dependent variables examined were age, marital status, language spoken at home, education, current tobacco and alcohol consumption, age at first sexual intercourse, whether 
taking medication for cardiovascular disease, and presence of diabetes.

\section{Statistical analysis}

Prevalence estimates of study variables were weighted for the probability of household selection (households with more phone lines were more likely to be contacted) and to adjust for the probability of selection within a household (men living in a household with more eligible men were less likely to be selected). Data were then weighted to match the Australian male population on the basis of age and area of residence based on estimates taken from the 2001 Australian Census. ${ }^{12}$ Data was analysed using SPSS version 12.

Key demographic variables and other variables previously shown to be associated with erectile dysfunction were examined using Pearson $\chi^{2}$ tests. Variables found to be associated with erectile dysfunction on univariate analyses were further entered into a logistic regression model in order to adjust for potential confounding factors. In the logistic regression analysis all variables were entered in one step and removed from the model according to the tolerance statistic (fitting the model using the "enter" criteria in SPSS for Windows 12.0). Adjusted odds ratios with their 95\% confidence intervals (CI) were then calculated.

\section{RESULTS}

A total of 8517 men (83.7\%) reported being sexually active in the previous 12 months. Of these, 8367 (98.2\%) responded to the question concerning erectile dysfunction. The mean age of this group was 37 years. Over half $(56.7 \%)$ of the respondents were married, $8.4 \%$ were separated or divorced, and $34.5 \%$ had never married. Most respondents were in fulltime employment $(74.2 \%), 10 \%$ worked part-time and $4.7 \%$ were unemployed. The majority (94.3\%) spoke English at home. Half $(50 \%)$ had finished secondary or vocational education, and a quarter of respondents had completed some form of post-secondary education.

Almost one in 10 of the respondents $(9.1 \%)$ reported that they had trouble keeping an erection when they wanted to, a difficulty which lasted for at least one month over the previous year. Over a quarter $(27.2 \%)$ of respondents were current smokers, with $20.9 \%$ smoking $\leqslant 20$ cigarettes per day and $6.3 \%$ smoking $>20$ cigarettes per day.

On univariate analysis, smoking was found to be significantly associated with erectile dysfunction $\left(\chi^{2}=17.45\right.$, $\mathrm{df}=2, \mathrm{p}<0.001)$. Erectile dysfunction was also associated with a number of demographic characteristics including age, marital status and education level. No association was found between erectile dysfunction and either language spoken at home or age at first intercourse. People with diabetes or taking medication for cardiovascular disease were also significantly associated with erectile dysfunction with unadjusted odds ratios of 1.57 (95\% CI 1.18 to 2.07 ) or 3.85 (95\% CI 3.14 to 4.71$)$, respectively. In contrast, moderate alcohol consumption (1-4 drinks per day) reduced unadjusted odds ratios of having erectile dysfunction.

Results of multivariate analysis are presented in table 1 . Age remained a significant factor after adjusting for the other variables, with a fivefold difference in adjusted odds ratios of having erectile dysfunction between the youngest and oldest age groups. Respondents who had completed secondary or vocational education were less likely to experience erectile dysfunction than those with a lower level of education (adjusted odds ratio $0.76,95 \%$ CI 0.64 to 0.92 ), but it was not the case for those having completed post-secondary education. Moderate alcohol consumption ( $1-4$ drinks a day) retained significance as an independent factor for erectile dysfunction in the multivariate analysis (adjusted odds ratio $0.36,95 \%$ CI 0.28 to 0.45$)$. Respondents taking medications for cardiovascular disease and those with diabetes were more likely to experience erectile dysfunction. However, only cardiovascular medication remained significant after adjustment for other variables.

Smoking was significantly associated with erectile dysfunction after adjusting for potential confounding factors. This association was strengthened as the number of cigarettes smoked increased. Compared with non-smokers, the adjusted odds ratios for erectile dysfunction were 1.24 (95\% CI 1.01 to $1.52, \mathrm{p}=0.04$ ) for those smoking $\leqslant 20$ cigarettes per day and 1.39 (95\% CI 1.05 to $1.83, \mathrm{p}=0.02$ ) for those smoking $>20$ cigarettes per day.

\section{DISCUSSION}

Our findings from a survey of a large representative sample of Australian men indicate that current smoking is significantly associated with erectile dysfunction and this association was strengthened as the number of cigarettes smoked increased. This finding is in keeping with a small number of previous population-based studies which provided some evidence of the relationship between erectile dysfunction and tobacco exposure levels. For example, the Massachusetts Male Aging Study ${ }^{9}$ found that passive exposure to cigarette smoke at both at home and work doubled the odds of incident erectile dysfunction (adjusted odds ratio 2.07, 95\% CI 1.04 to 4.13 ), whereas exposure within either setting did not. However, the authors did not examine the relationship between amount smoked and erectile dysfunction in current smokers. Gades et $a l^{13}$ examined the relationship between cumulative exposure (pack-years based on reported duration and intensity of smoking) and erectile dysfunction in 2115 randomly selected white men in Minnesota aged 40-79 years. The odds ratios for erectile dysfunction in men smoking 1-12.5 pack-years, 12.6-29.0 pack-years and $>29$ pack-years after adjusting for age and co-morbidities were $0.96,1.44$ and 1.60, respectively. However, odds ratios were not statistically significant in those men with low and moderate cumulative exposure and findings from a trend analysis were not reported. Neither years smoked nor cigarettes smoked daily were significant predictors of impotence in current smokers in the Vietnam Experience Study. ${ }^{10}$ This could be due to the limitation of its study population.

Our findings confirm previous research which has shown that erectile dysfunction to be an age-related condition that is more common in men with cardiovascular disease and/or diabetes, ${ }^{8}{ }^{14}$ although the latter did not retain significance in our study, after other factors were controlled for. This may be explained by the fact that our relatively young, populationbased sample (age 16-59 years) is likely to have included fewer and less severe cases of diabetes than previous studies. Modest alcohol intake appeared to confer an inverse relationship with erectile dysfunction in our respondents. This finding is consistent with the assertion that the risk factor profile for erectile dysfunction is similar to that for coronary heart disease. For example, the Massachusetts Male Aging Study found that overweight, hypertension and low physical activity levels were risk factors for erectile dysfunction. ${ }^{9}$ We were unable to control for these additional risk factors in our analysis, which are unlikely to be distributed equally within our sample. This may explain why better educated respondents were less likely to experience erectile dysfunction than those who did not complete secondary school.

\section{Strengths and weaknesses}

This study provides strong evidence of a relationship between levels of tobacco exposure in current smokers and erectile dysfunction. The significance of this finding is strengthened by the fact that our sample included men from a wide age range and that we were able to control for many of the 
Table 1 Association between tobacco consumption and erectile dysfunction

\begin{tabular}{|c|c|c|c|c|c|c|}
\hline \multirow[b]{2}{*}{ Study variables } & \multirow{2}{*}{$\begin{array}{l}\text { Characteristics of study } \\
\text { population weighted \% }\end{array}$} & \multicolumn{5}{|c|}{ Having had erectile dysfunction } \\
\hline & & $\%$ & Unadjusted OR $(95 \% \mathrm{Cl})$ & p Value & Adjusted OR $(95 \% \mathrm{CI})^{*}$ & p Value \\
\hline \multicolumn{7}{|l|}{ Tobacco consumption } \\
\hline Non-smoker & 72.8 & 8.8 & 1 & 0.43 & 1 & \\
\hline$\leqslant 20$ cigarettes per day & 20.9 & 9.4 & $0.93(0.54$ to 1.32$)$ & $<0.001$ & 1.24 (1.01 to 1.52$)$ & 0.04 \\
\hline$>20$ cigarettes per day & 6.3 & 14.7 & $1.67(1.11$ to 1.97$)$ & & 1.39 (1.05 to 1.83$)$ & 0.02 \\
\hline \multicolumn{7}{|l|}{ Age (years) } \\
\hline $16-19$ & 5.7 & 4.6 & 1 & 0.85 & 1 & \\
\hline 20-29 & 23.8 & 4.3 & $0.95(0.59$ to 1.55$)$ & 0.61 & $1.02(0.62$ to 1.68$)$ & 0.94 \\
\hline $30-39$ & 26.7 & 5.1 & $1.13(0.71$ to 1.81$)$ & $<0.001$ & $1.32(0.80$ to 2.18$)$ & 0.28 \\
\hline $40-49$ & 24.8 & 12.4 & 2.97 (1.89 to 4.67$)$ & $<0.001$ & $3.50(2.15$ to 5.70$)$ & $<0.001$ \\
\hline $50-59$ & 19.1 & 20.7 & 5.49 (3.51 to 8.60$)$ & & 5.96 (3.66 to 9.70$)$ & $<0.001$ \\
\hline \multicolumn{7}{|l|}{ Employment } \\
\hline Full time & 74.2 & 9.6 & 1 & 0.57 & 1 & \\
\hline Part time & 10.0 & 10.3 & 1.07 (0.85 to 1.36$)$ & 0.02 & $1.10(0.86$ to 1.42$)$ & 0.45 \\
\hline Unemployed & 4.7 & 13.2 & $1.42(1.05$ to 1.93$)$ & 0.15 & 1.45 (1.04 to 2.01$)$ & 0.03 \\
\hline Other & 10.0 & 8.1 & 0.83 (0.65 to 1.07$)$ & & $0.67(0.51$ to 0.88$)$ & 0.004 \\
\hline \multicolumn{7}{|l|}{ Education level } \\
\hline Pre-secondary & 25.5 & 12.5 & 1 & $<0.001$ & 1 & \\
\hline Secondary/vocational & 50.0 & 8.3 & $0.63(0.53$ to 0.74$)$ & 0.002 & $0.76(0.64$ to 0.92$)$ & 0.003 \\
\hline \multicolumn{6}{|l|}{ Alcohol consumption } & 0.29 \\
\hline Non-drinker & 10.3 & 18.2 & 1 & $<0.001$ & 1 & \\
\hline $1-4$ drinks per day & 78.7 & 8.6 & $0.42(0.34$ to 0.53$)$ & 0.15 & $0.36(0.28$ to 0.45$)$ & $<0.001$ \\
\hline $4+$ drinks per day & 11.1 & 15.5 & $0.83(0.78$ to 1.34$)$ & & $0.89(0.81$ to 1.34$)$ & 0.20 \\
\hline \multicolumn{7}{|l|}{ Taking meds for CVD } \\
\hline No & 93.2 & 8.4 & 1 & $<0.001$ & 1 & \\
\hline Yes & 6.8 & 26.1 & 3.85 (3.14 to 4.71$)$ & & $2.25(1.80$ to 2.81$)$ & $<0.001$ \\
\hline \multicolumn{7}{|l|}{ Diabetes } \\
\hline No & 98.0 & 9.4 & 1 & 0.002 & 1 & \\
\hline Yes & 2.0 & 24.5 & 1.57 (1.18 to 2.07$)$ & & $1.22(0.85$ to 1.75$)$ & 0.28 \\
\hline
\end{tabular}

*Adjusting other variables in the table.

$\mathrm{Cl}$, confidence interval; CVD, cardiovascular disease; OR odds ratio.

established risk factors for erectile dysfunction, including age, co-morbidities and alcohol use. However, we acknowledge the need to exercise caution in making inferences about causality based on cross-sectional surveys of this kind. The association found in this study between smoking and erectile dysfunction warrants further investigation to establish whether this relationship is causal.

A single-item, self-reported measure was employed to assess erectile dysfunction over the previous 12 months. The breadth of issues covered in the ASHR meant it was not feasible to ask more than one question in relation to erectile dysfunction. However, the question used conforms to the US National Institutes of Health definition of impotence-that is, an inability to achieve or maintain an erection sufficient for satisfactory sexual performance. ${ }^{15}$ Previous work suggests that questionnaires with one or two measures of erectile dysfunction correlate well with more detailed self-assessment tools. ${ }^{16}{ }^{17}$ Moreover, we employed a similar methodology and found broadly similar age-related prevalence figures for erectile dysfunction to those reported previously in large scale sexual health surveys conducted in the United States and Britain. ${ }^{18} 19$

Respondents who were not sexually active over the past 12 months (that is, had no sexual partners and did not masturbate) were not asked about erectile dysfunction ( $16.3 \%$ of the sample). It is possible that this may have been a source of selection bias in our study, given that we were unable to ascertain the prevalence and other determinants of erectile dysfunction in this group. Some of these men may have been sexually inactive because of erectile difficulties. However, bias due to the necessary exclusion of this group is likely to be minimal, as one third (33\%) of sexually inactive men in the ASHR were aged 16-19 years (among whom erectile dysfunction is uncommon). The prevalence of the other main risk factors for erectile dysfunction (smoking, alcohol use, cardiovascular disease and diabetes) was broadly similar in the sexually active and inactive group.

\section{Policy implications}

Erectile dysfunction is an important public health issue in Australia affecting around one million men..$^{20}$ The prevalence of erectile dysfunction and the proportion of men who seek treatment for it is bound to increase given the combined impacts of an ageing population, increasing social acceptability of the condition and therapeutic advances. The already considerable healthcare costs associated with the management of erectile dysfunction, which grew substantially in a number of countries after the introduction of sildenafil and related drugs, ${ }^{21}$ are likely to increase further. It is essential that available opportunities for prevention are acted on, such as reducing the number of men who smoke.

\section{What this paper adds}

Studies on smoking and erectile dysfunction have been documented, often with the limitations of small or selective samples. This study used a large, representative and relatively young general population, and found a significant association between smoking and erectile dysfunction. In particular, this association was strengthened as the number of cigarettes smoked increased. The association found in this study between smoking and erectile dysfunction warrants further investigation to establish whether this relationship is causal. Increasing awareness about the link between smoking and erectile dysfunction in combination with other strategies may increase motivation for more young men to quit smoking. 
Australia has one of the world's most comprehensive tobacco control strategies which is reflected in our relatively low smoking rates. ${ }^{22}$ However, to meet the ambitious targets set by some states for further reductions-for example, a $1 \%$ annual reduction in prevalence in the most populous state, New South Wales ${ }^{23}$-will require more effective targeting of high-risk groups. Younger men (aged 16-44 years) are more likely to smoke than other groups yet may be least likely to change their behaviour in response to conventional tobacco control approaches. Increasing awareness about the link between smoking and erectile dysfunction in combination with other strategies may increase motivation for more young men to quit smoking. Lower levels of smoking would probably result in a reduction of prevalence of erectile dysfunction which affects about one million men in Australia.

\section{ACKNOWLEDGEMENTS}

The Australian Study of Health and Relationships was made possible through funding from the Commonwealth Department of Health and Ageing, the Victorian Health Promotion Foundation, the health departments of New South Wales, Queensland and Western Australia, and the Central Sydney Area Health Service. CM was partly funded through a Staff Development Grant from Guy's and St Thomas' Charitable Foundation in London.

\section{Authors' affiliations}

C Millett, L M Wen, C Rissel, Health Promotion Unit (Eastern Zone), Sydney South West Area Health Service, NSW, Australia

A Smith, R de Visser, Australian Research Centre in Sex, Health and Society, La Trobe University, Victoria, Australia

J Richters, A Grulich, National Centre in HIV Social Research, University of NSW, Australia

Competing interests: None identified.

\section{REFERENCES}

1 Australian Institute of Health and Welfare. Statistics on drug use in Australia 2004, AlHW Cat.No.PHE 62 (Drug Statistics Series No.15). Canberra: AlHW, 2005
2 Centre for Epidemiology and Research, NSW Department of Health. New South Wales Adult Health Survey 2003. NSW Public Health Bull 2004;15(S4).

3 Gregoire A. ABC of sexual health. BMJ 1999;318:245-7.

4 Action on Smoking, Health (ASH) UK. Smoking and erectile dysfunction in men, www.ash.org.uk/html/health/html/impotent.html (Accessed May 25, 2005).

5 Davis R. The Marlboro Man needs Viagra. Tob Control 1998;7:227-9.

6 Tobacco Control Supersite. Picture gallery - graphical cigarette pack health warnings, http://tobacco.health.usyd.edu.au/site/supersite/resources/ docs/gallery_packwarnings.htm (Accessed December 21, 2005).

7 Tengs T, Osgood N. The link between smoking and impotence: two decades of evidence. Prev Med 2001;32:447-52.

8 McVary K, Carrier S, Wessells $\mathrm{H}$, et al. Smoking and erectile dysfunction: evidence based analysis. J Urology 2001;166:1624-32.

9 Feldman H, Johannes C, Derby C, et al. Erectile dysfunction and coronary risk factors: prospective results from the Massachusetts male aging study. Prev Med 2000;30:328-38

10 Mannino D, Klevens R, Flanders W. Cigarette smoking: an independent risk factor for impotence? Am J Epidemiology 1994;140:1003-8.

11 Smith A, Rissel C, Richters J, et al. Sex in Australia: the rationale and methods of the Australian study of health and relationships. Aust N Z J Public Health 2003;27:106-17.

12 Australian Bureau of Statistics. 2001 Australian Census of Population and Housing, http://www.abs.gov.au/websitedbs/d3310114.nsf/Home/Census (Accessed May 25, 2005).

13 Gades N, Nehra A, Jacobson D, et al. Association between smoking and erectile dysfunction: a population-based study. Am J Epidemiology 2005; 161:346-51

14 Russell S, Khandheria B, Nehra A. Erectile dysfunction and cardiovascular disease. Mayo Clin Proc 2004;79:782-94.

15 Anon. Impotence. NIH consensus development panel on impotence [NIH consensus conference]. JAMA 1993;270:83-90.

16 Derby C, Araujo A, Johannes C, et al. Measurement of erectile dysfunction in population-based studies: the use of a single question self-assessment in the Massachusetts male aging study. Int J Impot Res 2000;12:197-204.

17 O'Leary M, Fowler F, Lenderking W, et al. A brief male sexual function inventory for urology. Urology 1995;46:607-706.

18 Laumann E, Paik A, Rosen R. Sexual dysfunction in the United States. Prevalence and predictors. JAMA 1999;281:537-44.

19 Mercer C, Fenton K, Johnson A, et al. Sexual function problems and help seeking behaviour in Britain: national probability sample survey. BMJ 2003;327:426-7.

20 Lowy M. Erectile dysfunction in the Australian community. Med J Austr 1999;171:342-3.

21 Wilson E, McKeen E, Scuffham P, et al. The cost to the United Kingdom National Health Service of managing erectile dysfunction: the impact of sildenafil and prescribing restrictions. Pharmacoeconomics 2002;20:879-89.

22 Chapman S. Tobacco control. NSW Public Health Bull 2003;14:46-8.

23 Cancer Institute of NSW. The NSW Cancer Plan 2004-2006, Sydney. The Cancer Institute NSW, 2004 